\title{
Fatores de Modernização Agropecuária nos Municípios Brasileiros em 2006
}

\section{Factors of Agricultural Modernization in Brazilian Municipalities in 2006}

\author{
Rodrigo Peixoto da Silva ${ }^{\mathrm{a}}$ \\ Carlos Eduardo de Freitas Vian ${ }^{\mathrm{b}}$
}

\begin{abstract}
Resumo: Este trabalho identifica os aspectos relevantes da modernização agropecuária com base nas características de 4.535 municípios brasileiros no ano de 2006. Para isso, ajusta-se um modelo de análise fatorial considerando 30 variáveis para captar a adoção de "boas práticas" agropecuárias e o uso de insumos modernos. O processo de modernização é sintetizado em quatro fatores: uso intensivo da terra; capitalização e tecnificação da criação animal; tecnificação agrícola; e relação capital-trabalho. Os resultados apontam para a concentração regional do fator uso intensivo da terra no Sudeste, no estado do Paraná e na faixa litorânea do país, do fator tecnificação agrícola na região Sul e em partes do Sudeste e do fator relação capital-trabalho nas regiões Centro-Oeste e Sudeste. A capitalização e tecnificação da criação animal, por sua vez, é um aspecto que demonstra distribuição regional mais uniforme. A região nordeste é um caso preocupante com relação à modernização, uma vez que apresenta indicadores pífios em quase todos os aspectos identificados e que as políticas públicas adotadas no início dos anos 2000 se mostraram insuficientes para mitigar esse problema.
\end{abstract}

Palavras-chave: fatores de modernização; análise fatorial; política agrícola.

Abstract: This work identified the relevant aspects of agricultural modernization based on the characteristics of 4,535 Brazilian municipalities in 2006. A Factor Analysis model was adjusted, considering 30 variables to capture the adoption of agricultural "good practices" and the use of modern inputs. The modernization process was synthesized in four factors: Intensive land-use; Capitalization and technification of animal husbandry; Technification of agriculture; and Capital-labor ratio. The results pointed to a regional concentration of the Intensive land-use factor in the Southeast region, in the state of Parana and in the coastal strip of the country, of the Technification of agriculture factor in the South region and in parts of the Southeast region and of the Capital-labor ratio factor in the Midwest and Southeast regions. The Capitalization and technification of animal husbandry, in turn, is a factor that demonstrates more uniform regional distribution. The northeastern region is a worrying aspect in relation to modernization,

a Universidade de São Paulo (USP), Escola Superior de Agricultura "Luiz de Queiroz" (ESALQ), Centro de Estudos Avançados em Economia Aplicada (CEPEA). Piracicaba, São Paulo, Brasil.

b Universidade de São Paulo (USP), Escola Superior de Agricultura "Luiz de Queiroz" (ESALQ), Departamento de Economia, Administração e Sociologia Rural (LES). Piracicaba, São Paulo, Brasil. 
since it presented weak indicators in almost all aspects identified and the public policies adopted in the early 2000 s proved insufficient to mitigate this problem.

Keywords: modernization factors; factor analysis; agricultural policy.

JEL Classification: Q16; Q18; C38.

\section{Introdução}

A agropecuária representou, até o início do século XX, o setor dinâmico da economia brasileira e teve uma trajetória baseada na utilização extensiva de terra e mão de obra e na adoção de técnicas tradicionais até a década de 1950 (FRANCO; PEREIRA, 2008). As tecnologias mais sofisticadas se restringiam a casos como o do café para exportação (SILVA; BOTELHO, 2014).

A partir da crise de 1929, a política econômica brasileira foi orientada pela industrialização por substituição de importações, criando sua indústria de base e, após 1950, intensificando o processo de modernização da agropecuária e setores relacionados a jusante e a montante. Essa fase foi pautada em forte intervenção do Estado, com o objetivo de conectar os diversos setores da economia, facilitar a acumulação de capital (SILVA; BOTELHO, 2014) e expandir e diversificar a oferta agropecuária no mercado interno e externo "[...] através da modernização da base técnica, fortalecimento da agroindústria e incorporação de novas terras [...]” (BUAINAIN, 1999, p. 120-121).

De acordo com Almeida (1997), a modernização da agricultura esteve ancorada em quatro pilares: crescimento e desenvolvimento econômico e político; abertura técnica, econômica e cultural; especialização e dependência da produção a montante, a jusante e com a sociedade global; e surgimento de um perfil de agricultor individualista e competitivo.

Nas décadas de 1960 e 1970, o processo tomou seus mais fortes contornos (KAGEYAMA et al., 1990). Consolidou-se a partir do II Plano Nacional de Desenvolvimento (II PND - década de 1970) e "[...] visava desenvolver internamente o setor de insumos para a agricultura [...]” (FRANCO; PEREIRA, 2008, p. 189). Para tanto, o Estado utilizou-se de um conjunto de instrumentos como o crédito rural subsidiado, este com papel central, programas de pesquisa agronômica e extensão rural (SOUZA; LIMA, 2003), a política de garantia de preços mínimos, a política de seguro rural e as políticas de pesquisa e extensão agropecuária (BACHA, 2004).

De acordo com Bacha (2004, p. 65): "Durante as décadas de 1970 e 1980, o crédito rural beneficiou, principalmente, as culturas de exportação, as regiões Sul e Sudeste e os médios e grandes produtores rurais [...]". Esses produtores apresentavam o perfil adequado ao plano macroeconômico do Governo Federal de 
incentivo às exportações: os produtos integrados ao mercado internacional (soja, milho, café, cana-de-açúcar, trigo e arroz) eram cultivados no Centro-Sul brasileiro por médios e grandes produtores, que possuíam maior capacidade administrativa e facilidade na tomada de empréstimos (BACHA, 2004). O padrão tecnológico não foi totalmente absorvido pelos pequenos produtores, nem mesmo planejado para eles, devido às escalas mínimas de produção requeridas, à insuficiência de recursos próprios (produtivos e financeiros) e à dificuldade de acesso às fontes favoráveis de financiamento (SILVA et al., 1983).

A partir dos anos 1980, com o período de intensa crise econômica, diversos programas e políticas foram descontinuados ou reduzidos. Em meados de 1990, o governo passou também a orientar algumas das políticas no sentido de minimizar problemas como a elevada concentração de terras, de renda e a heterogeneidade produtiva no campo. A partir de 1994, o governo distribuiu 8,7 milhões de hectares para 370 mil famílias, valor superior à toda a terra distribuída entre 1964 e 1994 (HELFAND; REZENDE, 2001).

Foi criado o Programa Nacional de Fortalecimento da Agricultura Familiar (Pronaf) visando prover recursos financeiros para o desenvolvimento dessa grande parcela de produtores - 84,4\% em 2006 (INSTITUTO BRASILEIRO DE GEOGRAFIA E ESTATÍSTICA, 2009) -, que, a princípio, estariam desfavorecidos perante os demais. De acordo com Wedekin (2005), entre as safras 2002-2003 e 2004-2005, as operações do Pronaf cresceram de 926 mil para 1,62 milhões, enquanto o montante de recursos passou de $\mathrm{R} \$ 2,2$ bilhões para $\mathrm{R} \$ 6,2$ bilhões.

O marco da retomada das políticas de crédito aos produtores rurais foi, no entanto, a maior participação do Banco Nacional de Desenvolvimento Econômico e Social (BNDES) no financiamento rural, apoiado nos recursos do Fundo de Amparo ao Trabalhador (FAT). De acordo com Wedekin (2005), o financiamento via Mapa-BNDES passou de $R \$ 342$ milhões, na safra 1999-2000, para $R \$ 5,2$ bilhões, na safra 2004-2005, e, somando-se os demais recursos, o crédito para investimento na agropecuária atingiu os $\mathrm{R} \$ 8,0$ bilhões na safra 2004-2005.

A modernização agropecuária brasileira tem sido abordada empiricamente sob diferentes recortes espaço-temporais na literatura econômica. Hoffmann e Kassouf (1989a) caracterizam a agropecuária de 332 microrregiões homogêneas (MRH) brasileiras - exclusive a região Norte -, com base nos dados do Censo Agropecuário 1980. Os autores adotaram a metodologia de análise fatorial para "resumir" 32 variáveis relativas ao uso de insumos considerados modernos, como o uso de tratores, fertilizantes e defensivos agrícolas em dois fatores principais que consideraram representar a intensidade de exploração da terra e a relação capital/ trabalho. Demonstraram a grande disparidade entre as microrregiões pertencentes à região Nordeste e as demais MRHs. 
Hoffmann (1992) adota um recorte espaço-temporal que considerava 157 MRHs do Brasil e os anos de 1970, 1975 e 1980 para a análise. Os resultados corroboram aqueles encontrados no trabalho anterior e demonstram uma dinâmica regional diferenciada da modernização. Hoffmann e Kageyama (1985) avaliam os efeitos da modernização sobre o rendimento médio, índice de pobreza e desigualdade de renda com base nos dados do Censo Agropecuário 1975 e no Censo Demográfico 1980, apontando que o grau de modernização está associado positivamente ao nível de renda per capita e à desigualdade de renda no setor agropecuário e apresenta relação negativa com o nível de pobreza rural.

Hoffmann e Kassouf (1989b) calculam os índices de modernização por meio de análise fatorial e avaliam seu efeito sobre índices de desigualdade de renda e de pobreza, considerando $158 \mathrm{MRHs}$ de oito estados brasileiros, corroborando os resultados de Hoffmann e Kageyama (1985).

Souza e Lima (2003) utilizam-se do mesmo aparato metodológico para abordar a intensidade e dinâmica da modernização agrícola no Brasil no período de 1970 a 1995, demonstrando as disparidades da modernização entre as unidades da federação. Os autores apontam para um processo de modernização menos intenso na maioria dos estados do Norte e Nordeste e mais intenso na região Centro-Sul. Além disso, apontam para uma expressiva retração desse processo na década de 1980, devido à contração do crédito rural e à elevação de seu custo, embora o processo de modernização em si não tenha sido totalmente interrompido.

Balsan (2006) destaca os impactos ambientais e socioeconômicos da modernização, como o agravamento das questões ambientais e a insustentabilidade do uso de agrotóxicos, o inchamento das cidades, a concentração de terras e da renda e a intensificação das lutas sociais. Destaca, ainda, as disparidades regionais que deram base ao processo de modernização e se intensificaram por meio dele, dando-o as denominações de modernização dolorosa, modernização conservadora e modernização excludente.

Corrêa e Figueiredo (2006) analisam a modernização da agricultura brasileira no início dos anos 2000 e ressaltam que a desigualdade regional em termos de adoção de tecnologia e modernização, explicitada nos trabalhos de Hoffmann (1992) e Hoffmann e Kassouf (1989a, 1989b), manteve-se presente no Brasil e que os anos 2000 foram marcados pelo aumento da intensidade do uso de capital e da produtividade, especialmente no Centro-Oeste, dinâmica que, novamente, a região Nordeste não acompanhou.

Outros trabalhos destacaram que esse processo foi heterogêneo também dentro dos estados brasileiros. Souza e Khan (2001, p. 105) analisam o caso do Maranhão, caracterizado pelo grande contraste do nível tecnológico empregado em seus municípios: "[...] 131 municípios do total de 136, apresentaram níveis tecnológicos na agricultura inferiores aos 50\% do nível tecnológico verificado no mu- 
nicípio mais modernizado [...]”. Franco e Pereira (2008) analisam o caso do Paraná e argumentam que, como o processo de modernização foi intensificado nos anos 1960 e, sobretudo nos anos 1970, o Paraná realizou a reestruturação necessária para que, na chamada década perdida (1980) e no período de abertura comercial e intensa concorrência internacional (anos 1990), conseguisse superar os desafios enfrentados. Por outro lado, Llanilo et al. (2006) classificam os municípios paranaenses em 11 grupos distintos em termos de modernização, demonstrando que a heterogeneidade oriunda do processo ocorre mesmo dentro do estado. Fajardo (2008), por sua vez, destaca o papel das cooperativas no processo de modernização agrícola paranaense, responsáveis pela rápida adesão dos produtores associados às inovações tecnológicas.

Freitas, Paz e Nicola (2007) analisam o caso do Rio Grande do Sul, destacando o papel da produtividade do trabalho, do nível de capital empregado e da irrigação. Os autores demonstram que o cultivo do arroz irrigado foi a atividade mais favorecida no processo de modernização e, consequentemente, os municípios que possuem essa cultura em sua pauta produtiva estão em um estágio superior de desenvolvimento. Todavia, as disparidades entre os municípios permanecem, delineando um ambiente atrasado na fronteira noroeste (próximo à Santa Catarina) e moderno na fronteira oeste e divisa com o Uruguai.

Cruz, Ribeiro e Lima (2006) utilizam-se de análise fatorial e análise de cluster para tratar o tema na mesorregião de Campo das Vertentes (MG), chegando a quatro fatores: o uso da terra; a relação capital/trabalho; financiamentos e despesas gerais; e despesas com assistência técnica e insumos. Os resultados mostram que 59\% dos municípios analisados apresentaram baixos níveis de modernização. Ainda sobre o estado de Minas Gerais, Campos, Pereira e Teixeira (2014) identificam quatro trajetórias distintas da produção agropecuária entre suas microrregiões, todas tendo em comum a modernização e mudanças tecnológicas, embora diferenciem-se em termos de adoção de práticas de conservação do meio ambiente.

Por um lado, sob uma menor desagregação regional (unidades federativas ou MRHs), a região Centro-Sul é apontada pela literatura como aquela que mais se beneficiou do processo, com ganhos de produtividade, inserção internacional e aumento da competitividade, transformando o Brasil em um dos principais players internacionais do agronegócio. Por outro lado, sob um recorte regional mais restrito e com maior desagregação regional dos dados (municípios), a literatura traz evidências de heterogeneidade produtiva e econômica dentro dos próprios estados, mesmo naqueles que representam a vanguarda da modernização agropecuária brasileira. Dessa forma, os resultados dessas duas classes de trabalhos são de difícil comparação e atualização.

Nesse sentido, o objetivo do presente trabalho foi identificar os aspectos relevantes da modernização agropecuária presentes no ano de 2006, com desagre- 
gação ao nível municipal e abrangência de mais de 80\% dos municípios brasileiros (4.535 municípios), ${ }^{1}$ realizando a comparação entre esses municípios em cada um dos aspectos identificados e permitindo melhor entendimento dos determinantes e do grau de modernização da agropecuária brasileira, bem como do grau de heterogeneidade entre e dentro das regiões.

A relevância da temática se justifica pelos efeitos ambíguos atribuídos pela literatura ao processo de modernização (GONZALES; COSTA, 1998; MARTINE, 1991; KAGEYAMA, 1986; BALSAN, 2006; BUAINAIM, 1997; HOFFMANN; KAGEYAMA, 1985; SILVA, 1996; REZENDE, 2006).

\section{Metodologia}

A análise fatorial consiste em um conjunto de métodos e técnicas de análise estatística com objetivo de resumir a informação relevante de um conjunto grande de variáveis observáveis em um número reduzido de variáveis latentes, maximizando a parcela explicada da variância do conjunto de variáveis originais. Dadas as múltiplas facetas do processo de modernização, esse método é de grande interesse para a análise e foi utilizado por diversos trabalhos, como os de Campos, Pereira e Teixeira (2014), Corrêa e Figueiredo (2006), Cruz, Ribeiro e Lima (2006), Franco e Pereira (2008), Hoffmann e Kageyama (1985) e Hoffmann e Kassouf (1989a; 1989b).

\subsection{O Modelo de Análise Fatorial}

Assume-se que a relação entre as variáveis observáveis e os fatores seja linear (HOFFMANN, 2002). Para eliminar os efeitos de escala e unidades de medida, as variáveis são padronizadas, o que consiste em "[...] expressar em desvios-padrão, os desvios das observações originais em relação à sua média [...]" (SOUZA; LIMA, 2003, p. 798), de forma que todas as variáveis tenham a mesma variância e sua participação na determinação dos fatores dependa apenas das suas correlações com as demais variáveis (HOFFMANN, 2002).

O modelo básico de análise fatorial é descrito conforme a equação 1:

$$
X=A F+U Y
$$

Em que $X$ é a matriz padronizada de $k$ variáveis por $n$ observações; $F$ é a matriz $m \times n$ de fatores comuns; $Y$ é a matriz $k \times n$ de fatores específicos; $A$ é a matriz

$1 \quad$ A análise se deu sobre 4.535 municípios devido à indisponibilidade de dados sobre todos os 30 indicadores analisados para os demais municípios brasileiros no Censo Agropecuário de 2006. 
$k \times m$ de coeficientes dos fatores comuns e U é a matriz $\mathrm{n} \times \mathrm{k}$ de coeficientes dos fatores específicos.

$$
\begin{aligned}
& X=\left[\begin{array}{cccc}
x_{11} & x_{12} & \ldots & x_{1 n} \\
x_{21} & x_{22} & \ldots & x_{2 n} \\
\ldots & \ldots & \ldots & \ldots \\
x_{k 1} & x_{k 2} & \ldots & x_{k n}
\end{array}\right], \quad F=\left[\begin{array}{cccc}
f_{11} & f_{12} & \ldots & f_{1 n} \\
f_{21} & f_{22} & \ldots & f_{2 n} \\
\ldots . & \ldots & \ldots & \ldots \\
f_{m 1} & f_{m 2} & \ldots & f_{m n}
\end{array}\right] \\
& Y=\left[\begin{array}{cccc}
y_{11} & y_{12} & \ldots & y_{1 n} \\
y_{21} & y_{22} & \ldots & y_{2 n} \\
\ldots & \ldots . & \ldots & \ldots \\
y_{k 1} & y_{k 2} & \ldots & y_{k n}
\end{array}\right], \quad A=\left[\begin{array}{cccc}
a_{11} & a_{12} & \ldots & a_{1 m} \\
a_{21} & a_{22} & \ldots & a_{2 m} \\
\ldots & \ldots & \ldots . & \ldots \\
a_{k 1} & a_{k 2} & \ldots & a_{k m}
\end{array}\right] \\
& U=\left[\begin{array}{cccc}
u_{1} & 0 & \ldots & 0 \\
0 & u_{2} & \ldots & 0 \\
\ldots & \ldots & \ldots & \ldots \\
0 & 0 & \ldots & u_{k}
\end{array}\right]
\end{aligned}
$$

Com exceção de métodos de extração de fatores oblíquos, as seguintes condições de ortogonalidade devem ser respeitadas:

$$
\begin{aligned}
& Y Y^{\prime}=I_{k} \\
& F F^{\prime}=I_{m} \\
& F Y^{\prime}=0
\end{aligned}
$$

A equação 3 atende à condição de variância unitária e ortogonalidade entre os fatores específicos; a equação 4 atende as mesmas condições para o caso dos fatores comuns; e a equação 5 garante a ortogonalidade entre os fatores comuns e específicos. Seja $R$ a matriz de correlações de Pearson de $X$, então:

$$
R=X X^{\prime}=A A^{\prime}+U U^{\prime}=A A^{\prime}+U^{2}
$$

E considerando-se um elemento da diagonal de $R$, chega-se a:

$$
1=\sum_{j=1}^{n} x_{i j}^{2}=\sum_{p=1}^{m} a_{i p}^{2}+u_{i}^{2} \quad \text { para } i=1, \ldots, k
$$

Os dois últimos termos da equação 7 representam, respectivamente, as proporções das variâncias de $x_{i}$ devidas a cada grupo de fatores. A parte associada 
aos $m$ fatores comuns é denominada comunalidade (equação 8) e a parte da i-ésima variável associada ao fator específico é denominada especificidade $\left(u_{i}^{2}\right)$.

$$
h_{i}^{2}=\sum_{p=1}^{m} a_{i p}^{2}
$$

Os coeficientes aip são denominados cargas fatoriais e compõem a matriz estrutura. Eles correspondem à correlação simples entre a variável $x_{i}$ e o fator $f_{p}$ no caso de rotações ortogonais de fatores que correspondem a coeficientes de regressões no caso de rotações oblíquas.

No contexto deste trabalho, os escores fatoriais representam o grau de modernização agropecuária de cada município sob cada aspecto (fator) resultante da análise. São obtidos pela multiplicação do vetor de cargas fatoriais, após a rotação de fatores, pela matriz de dados normalizados, conforme a equação 9:

$$
F_{j}^{p}=\sum_{i=1}^{k} b_{i} \cdot X_{i j}
$$

em que $F_{j p}$ é o escore fatorial do município $j$ para o fator $p, b_{i}$ são as cargas fatoriais após a rotação de fatores e $X_{i j}$ são os dados normalizados.

A definição do número de fatores a ser extraído deve obedecer a algum critério, como o grau de explicação da variância associado com cada fator (critério do autovalor) ou o incremento marginal de cada fator no modelo (gráfico de declive ou scree plot). Fatores com autovalor inferior a um possuem um incremento na explicação da variância inferior ao das variáveis originais, sendo descartados. Neste trabalho, foram utilizados três critérios: o gráfico de declive, o critério do autovalor e a estimativa do número ótimo de fatores por meio de validação cruzada, ${ }^{2}$ conforme proposto por Josse e Husson (2012). ${ }^{3}$

\subsection{Adequação dos Dados}

Para se avaliar a adequação dos dados à análise fatorial, foi calculado o índice de Kaiser-Mayer-Olkin (equação 10), que assume valores entre zero (inadequa-

2 Consiste na decomposição dos autovalores com base no particionamento da matriz de dados e exclusão de uma ou mais partições. A partir daí, as propriedades das amostras removidas são previstas pelos parâmetros estimados e os resíduos obtidos são computados e comparados, determinando-se o modelo de maior acurácia.

3 A proposta de Josse e Husson (2012) consiste em uma aproximação ao método de validação cruzada leave-one-out com a vantagem de apresentar menor custo computacional em amostras grandes. 
ção) e um (perfeita adequação) e, convencionalmente, são aceitos valores acima de 0,5 para julgar a amostra como adequada:

$$
K M O=\frac{\sum_{i=1}^{k} \sum_{t \neq i} r^{2}\left(x_{i}, x_{t}\right)}{\sum_{i=1}^{k} \sum_{t \neq i} r^{2}\left(x_{i}, x_{t}\right)+\sum_{i=1}^{k} \sum_{t \neq i} \pi^{2}\left(x_{i}, x_{t}\right)}
$$

em que $r\left(x_{i}, x_{t}\right)$ é o coeficiente de correlação entre $x_{i}$ e $x_{t}$ e $\pi\left(x_{i}, x_{t}\right)$ é o coeficiente de correlação parcial entre $x_{i}$ e $x_{t}$, dadas as demais variáveis.

Também foi realizado o teste $T$ de esfericidade de Bartlett, com hipótese nula de que a matriz de correlação é uma matriz identidade, implicando na ortogonalidade das variáveis e impossibilitando sua representação por meio de fatores comuns.

Obtidos os resultados da análise fatorial, utiliza-se comumente algum método de rotação de fatores para aproximar o respectivo fator obtido do feixe de variáveis ao qual está mais correlacionado, facilitando a interpretação e mantendo a proporção total explicada da variância dos dados.

Os métodos de rotação de fatores comumente utilizados são: varimax - rotação ortogonal que minimiza a ocorrência de uma variável possuir altas cargas fatorais para diferentes fatores; quartimax - rotação ortogonal que minimiza o número de fatores necessários para explicar satisfatoriamente cada variável (CORRAR, PAULO; DIAS FILHO, 2012); equimax: rotação ortogonal ponderada dos métodos varimax e quartimax; direct oblimin - rotação oblíqua em um estágio; e promax - rotação em dois estágios que parte de uma matriz de rotação ortogonal que minimiza o número de variáveis com cargas fatoriais elevadas em mais de um fator (primeiro estágio) e, então, realiza uma rotação oblíqua, minimizando as cargas fatoriais de menor valor e reduzindo o número de variáveis complexas, caracterizadas por elevadas cargas fatoriais em mais de um fator (cross-loading) (JACKSON, 2005). Foi adotado, neste trabalho, o método promax. Todos os procedimentos foram efetuados por meio do software $R$ (versão 3.4.3) e com o uso dos pacotes "stats", "psych", "GPArotation", "FactoMiner".

\subsection{Definição das Variáveis}

As variáveis elencam os chamados insumos modernos utilizados na agropecuária e estão, em grande medida, baseadas nos trabalhos de Hoffmann e Kassouf (1989a; 1989b), Souza e Lima (2003) e Campos, Pereira e Teixeira (2014). Algumas variáveis foram incrementadas e/ou modificadas visando maior aproximação com a realidade e aproveitamento das informações disponíveis, uma vez que os dados do Censo Agropecuário 2006 (IBGE, 2009) permitem tal exploração.

Diversas das variáveis utilizadas são compostas por razões, nas quais os denominadores são: o total de estabelecimentos agropecuários do município (TE); a 
área total de pastagem (AP); a área aproveitável para práticas agropecuárias (AA); área de lavoura permanente e temporária; (AL) e o pessoal ocupado nos estabelecimentos expresso em equivalente-homem-ano (EHA). Esse procedimento foi adotado visando estabelecer medidas de intensidade do uso de fatores e insumos produtivos nos municípios, minimizando a heterogeneidade oriunda das diferenças de escala existente entre municípios maiores e menores.

Hoffmann e Kassouf (1989a; 1989b) utilizam-se do conceito de equivalente-homem para equalizar a força de trabalho exercida por mulheres não assalariadas e crianças na agricultura, com base em metodologia proposta por Silva e Kageyama (1983). Kageyama, Bergamasco e Oliveira (2014), por outro lado, realizam uma outra ponderação para a força de trabalho ao longo de todo o ano nos estabelecimentos. Para isso, as autoras levam em consideração a quantidade média de dias trabalhados ao longo do ano, chegando ao conceito de equivalente-ano. Este trabalho uniu as duas ponderações, visando uma medida mais acurada da força de trabalho com o conceito de equivalente-homem-ano, ${ }^{4}$ descrito pela equação 11 :

$$
\begin{aligned}
E H A_{i}=\left(H_{i}+0,8 \cdot M_{i}\right. & \left.+0,6 \cdot C_{i}\right)\left(0,08 \cdot T_{(0-60) i}+0,33 \cdot T_{(60-180) i}\right. \\
& \left.+0,75 \cdot T_{(180-360) i}\right)
\end{aligned}
$$

na qual $\mathrm{Hi}, \mathrm{Mi}$ e $\mathrm{Ci}$ são as porcentagens de homens, mulheres e crianças, respectivamente, que compõem o pessoal ocupado nos estabelecimentos agropecuários do município $i ; T_{(0-60) i}, T_{(61-180)}$ i e $T_{(181-360) i}$ são as quantidades de pessoas que trabalharam de zero a 60 dias, de 61 a 180 dias e de 181 a 360 dias, respectivamente, ao longo do ano.

O nível de escolaridade médio das pessoas que dirigem os estabelecimentos em um determinado município $i$ foi definido como a soma das porcentagens de dirigentes em cada grau de escolaridade, ponderada por uma escala discreta de zero a 5, na qual zero significa o menor nível de escolaridade e cinco, o maior, e dividida pelo maior valor de ponderação, conforme a equação 12:

$$
N E_{i}=\frac{0 . A_{i}+1 \cdot B_{i}+2 \cdot C_{i}+3 \cdot D_{i}+4 \cdot E_{i}+5 \cdot F_{i}}{5}
$$

na qual $A_{i}$ é a porcentagem de dirigentes que não sabe ler e escrever em um município $i$ qualquer; $B_{i}$ é a porcentagem de dirigentes que não têm formação, mas sabem ler e escrever; $C_{i}$ é a porcentagem de dirigentes que possui ensino fundamental incompleto ou participou de algum programa para alfabetização de

$4 \quad$ O procedimento consiste em realizar a ponderação de Silva e Kageyama (1983) e, então, ponderar essa nova variável pela fração de ano trabalhada, conforme Kageyama, Bergamasco e Oliveira (2014). 
adultos; $D_{i}$ é a porcentagem de dirigentes que possui ensino fundamental completo; $E_{i}$ é a porcentagem de dirigentes que possui ensino médio completo (técnico ou não); e $F_{i}$ é a porcentagem de dirigentes que possui formação superior. Esse índice possui o intervalo [0;1]. O limite inferior é obtido quando a totalidade dos dirigentes de um município não sabe ler e escrever e o limite superior é obtido quando a totalidade desses dirigentes possui formação superior.

Essa escala a priori visou diferenciar os graus de escolaridade entre os dirigentes de estabelecimentos agropecuários dos municípios. Embora relativamente arbitrária, a forma linear foi adotada para permitir que o índice fosse estabelecido em um intervalo entre zero e um, diferenciando entre os variados graus de escolaridade e facilitando sua interpretação. O mesmo procedimento foi adotado em outros indicadores, como pode ser notado a seguir.

O nível de orientação técnica recebida pelas pessoas que dirigem os estabelecimentos foi definido como a soma das porcentagens de dirigentes em cada classe de orientação, ponderada por uma escala discreta de zero a dois, na qual zero representa o caso em não há orientação técnica e dois representa o caso em que há orientação técnica regularmente, dividida pelo maior fator de ponderação, conforme a equação 13:

$$
O T_{i}=\frac{0 . N R_{i}+1 \cdot R O_{i}+2 \cdot R R_{i}}{2}
$$

em que $N R_{i}$ é a porcentagem de dirigentes que não recebeu orientação técnica; $R O_{i}$ é a porcentagem de dirigentes que recebeu orientação técnica ocasionalmente; e $R R_{i}$ é a porcentagem de dirigentes que recebeu orientação técnica regularmente. Novamente, o intervalo desse índice é [0;1], no qual o valor zero é obtido quando a totalidade dos dirigentes dos estabelecimentos de um município não recebe qualquer orientação técnica e o valor dois é obtido quando essa totalidade recebe orientação técnica regularmente.

O nível de adoção de suplementação animal foi definido conforme a equação 14:

$$
S_{i}=\frac{0 . N U_{i}+1 \cdot U S_{i}+2 \cdot U R_{i}}{2}
$$

em que $N U_{i}$ é a porcentagem de estabelecimentos que não utiliza suplementação animal em um município i; $U S_{i}$ é a porcentagem de estabelecimentos que utiliza sal como suplementação animal; e $U R_{i}$ é a porcentagem de estabelecimentos que utiliza ração, grãos e subprodutos agroindustriais como suplementação animal. A interpretação e intervalo são análogos aos casos anteriores. 
O índice de integração com o mercado foi definido conforme a equação (15):

$$
I I_{i}=\frac{0 . N I_{i}+1 \cdot P I_{i}+2 \cdot I_{i}+3 \cdot M I_{i}}{3}
$$

em que $\mathrm{NI}_{i}$ é a porcentagem de estabelecimentos que não declararam o seu grau de integração com o mercado; $P I_{i}$ é a porcentagem de estabelecimentos pouco integrados ao mercado (a receita da atividade agropecuária é inferior a 50\% do valor de produção); $I_{i}$ é a porcentagem de estabelecimentos integrados ao mercado (a receita está entre 50\% e 90\% do valor de produção); e $M I_{i}$ é a porcentagem de estabelecimentos muito integrados em um determinado município i (a receita é superior a $90 \%$ do valor de produção). O intervalo e a interpretação desse índice são análogos aos casos anteriores.

Todas as variáveis selecionadas para análise foram ponderadas pelo PIB da agropecuária do respectivo município, de forma a considerar o peso econômico de cada município na determinação dos fatores de modernização: "A ponderação também pode ser justificada como uma tentativa de levar em consideração a heterocedasticia dos indicadores de modernização [...]" (HOFFMANN; KASSOUF, 1989a, p. 14). Todos os dados utilizados para o cálculo dos 30 indicadores analisados neste trabalho são oriundos do Censo Agropecuário 2006, do Instituto Brasileiro de Geografia e Estatística (IBGE, 2009), e as variáveis são descritas a seguir:

X1 - estabelecimentos que utilizaram força de trabalho mecânica/TE;

$\mathrm{X} 2$ - área de pastagem plantada/AP;

X3 - área trabalhada/AA;

X4 - área com lavouras permanentes e temporárias/AA;

X5 - número de tratores/EHA;

X6 - número de máquinas e implementos agrícolas/EHA;

$\mathrm{X} 7$ - estabelecimentos que tiveram financiamentos no ano de referência/TE;

$\mathrm{X} 8$ - estabelecimentos que realizaram despesas com combustíveis/TE;

X9 - estabelecimentos que utilizaram técnicas de plantio em nível/TE;

$\mathrm{X} 10$ - estabelecimentos que utilizaram técnicas de plantio direto na palha/TE;

X11 - estabelecimentos que utilizaram técnicas de rotação de cultura/TE;

$\mathrm{X} 12$ - valor dos veículos, tratores, máquinas e implementos/AL;

X13 - valor dos veículos, tratores, máquinas e implementos/EHA;

X14 - estabelecimentos que realizaram despesas com sal e ração para animais/TE;

X15 - PIB da agropecuária/AA;

X16 - PIB da agropecuária/EHA; 
$\mathrm{X} 17$ - estabelecimentos que realizaram despesas com adubos/TE;

X18 - estabelecimentos que realizaram despesas com corretivos do solo/TE;

$\mathrm{X} 19$ - estabelecimentos que realizaram despesas com sementes e mudas/TE;

X20 - estabelecimentos que realizaram despesas com agrotóxicos/TE;

$\mathrm{X} 21$ - estabelecimentos que realizaram despesas com compra de animais/TE;

$\mathrm{X} 22$ - estabelecimentos que realizaram despesas com medicamentos para animais/TE;

X23 - estabelecimentos que utilizaram energia elétrica/TE;

X24 - índice médio do nível de escolaridade da pessoa que dirige o estabelecimento;

X25 - índice médio do nível de orientação técnica recebida pela pessoa que dirige o estabelecimento;

X26 - índice médio de uso de suplementação animal;

X27 - estabelecimentos muito especializados/TE;

$\mathrm{X} 28$ - estabelecimentos especializados/TE;

X29 - estabelecimentos associados à cooperativa ou entidades de classe/TE;

X30 - índice médio de integração com o mercado.

A Tabela 1 traz as estatísticas descritivas das variáveis selecionadas para um conjunto de 4.535 municípios brasileiros, que representam todas as regiões político-administrativas.

Tabela 1 - Estatísticas descritivas das variáveis selecionadas (não ponderadas)

\begin{tabular}{lccccccc}
\hline Variável & $\begin{array}{c}\text { Unidade } \\
\text { de medida }\end{array}$ & Média & Mediana & $\begin{array}{c}\text { Desvio } \\
\text { padrão }\end{array}$ & CV $^{*}$ & Mínimo & Máximo \\
\hline X1 & $\%$ & 0,37 & 0,36 & 0,24 & 0,65 & 0,00 & 0,98 \\
X2 & $\%$ & 0,50 & 0,50 & 0,30 & 0,60 & 0,00 & 1,00 \\
X3 & $\%$ & 0,50 & 0,50 & 0,21 & 0,42 & 0,01 & 0,99 \\
X4 & $\%$ & 0,26 & 0,19 & 0,22 & 0,85 & 0,00 & 0,96 \\
X5 & Un/EHA & 0,12 & 0,07 & 0,13 & 1,08 & 0,00 & 0,90 \\
X6 & Un/EHA & 0,59 & 0,43 & 0,56 & 0,95 & 0,00 & 3,68 \\
X7 & $\%$ & 0,19 & 0,15 & 0,15 & 0,79 & 0,00 & 0,85 \\
X8 & $\%$ & 0,51 & 0,52 & 0,20 & 0,39 & 0,00 & 0,95 \\
X9 & $\%$ & 0,32 & 0,28 & 0,23 & 0,72 & 0,00 & 0,99 \\
X10 & $\%$ & 0,13 & 0,03 & 0,22 & 1,69 & 0,00 & 0,96 \\
X11 & $\%$ & 0,14 & 0,06 & 0,18 & 1,29 & 0,00 & 0,96 \\
X12 & $\mathrm{R} \$$ mil/ha & 1,03 & 0,78 & 1,30 & 1,26 & 0,04 & 56,92 \\
X13 & $\mathrm{R} \$$ mil/EHA & 24,98 & 15,61 & 36,22 & 1,45 & 0,48 & 883,88 \\
X14 & $\%$ & 0,43 & 0,44 & 0,24 & 0,56 & 0,00 & 0,96 \\
\hline
\end{tabular}

Continua... 


\begin{tabular}{lccccccc}
\hline Variável & $\begin{array}{c}\text { Unidade } \\
\text { de medida }\end{array}$ & Média & Mediana & $\begin{array}{c}\text { Desvio } \\
\text { padrão }\end{array}$ & CV* & Mínimo & Máximo \\
\hline X15 & R \$ mil/ha & 0,70 & 0,43 & 0,92 & 1,31 & 0,02 & 17,98 \\
X16 & R\$ mil/EHA & 14,88 & 10,65 & 17,71 & 1,19 & 0,44 & 315,70 \\
X17 & $\%$ & 0,37 & 0,34 & 0,29 & 0,78 & 0,00 & 0,99 \\
X18 & $\%$ & 0,13 & 0,09 & 0,13 & 1,00 & 0,00 & 0,70 \\
X19 & $\%$ & 0,17 & 0,11 & 0,18 & 1,06 & 0,00 & 0,91 \\
X20 & $\%$ & 0,31 & 0,23 & 0,26 & 0,84 & 0,00 & 0,98 \\
X21 & $\%$ & 0,25 & 0,22 & 0,14 & 0,56 & 0,02 & 0,95 \\
X22 & $\%$ & 0,62 & 0,66 & 0,22 & 0,35 & 0,00 & 0,98 \\
X23 & $\%$ & 0,75 & 0,81 & 0,20 & 0,27 & 0,02 & 1,00 \\
X24 & Índice & 0,41 & 0,43 & 0,13 & 0,32 & 0,10 & 0,83 \\
X25 & Índice & 0,22 & 0,19 & 0,18 & 0,82 & 0,00 & 0,86 \\
X26 & Índice & 0,62 & 0,63 & 0,10 & 0,16 & 0,00 & 1,00 \\
X27 & $\%$ & 0,23 & 0,22 & 0,14 & 0,61 & 0,00 & 0,89 \\
X28 & $\%$ & 0,37 & 0,36 & 0,11 & 0,30 & 0,05 & 0,82 \\
X29 & $\%$ & 0,40 & 0,39 & 0,22 & 0,55 & 0,00 & 0,98 \\
X30 & Índice & 0,59 & 0,58 & 0,12 & 0,20 & 0,13 & 0,96 \\
\hline
\end{tabular}

Fonte: Elaboração própria a partir do Censo Agropecuário 2006 (IBGE, 2009).

Nota: *CV: coeficiente de variação.

O percentual médio de estabelecimentos que faz uso de força mecânica (X1) nos municípios da amostra é de $37 \%$, e a mediana indica que, em metade dos municípios, esse percentual é inferior a 36\%, demonstrando potencial de mecanização. O número médio de tratores por $\mathrm{EHA}$ (X5) apresentou valor de 0,12, o que equivale a cerca de um trator para cada oito trabalhadores. No entanto, a mediana de 0,07 revela que, em metade dos municípios da amostra, essa relação é inferior a um trator para cada 14 trabalhadores. É baixo também o número médio de máquinas e implementos por EHA (X6), com média de 0,59 e mediana de 0,43.

$\mathrm{O}$ valor médio desembolsado em máquinas e equipamentos diverge consideravelmente entre os municípios. O valor médio por área de lavoura (X12) é de R\$ $1.030,00 / \mathrm{ha}$, com mediana de $\mathrm{R} \$ 780,00 / \mathrm{ha}$, enquanto existem municípios nos quais o desembolso médio com máquinas e equipamentos por hectare se aproxima dos $\mathrm{R} \$$ 57 mil. O desembolso médio em máquinas e equipamentos por EHA (X13) é de aproximadamente $\mathrm{R} \$ 25$ mil e também apresenta grande amplitude entre os municípios.

Os percentuais médios de estabelecimentos que realizaram gastos com combustíveis (X8) ou energia elétrica (X23) são de 51\% e 75\%, respectivamente, apontando para uma maior difusão no uso dessas fontes de energia. 
Com relação à proporção de áreas de pastagem plantada (X2), a distribuição entre os municípios apresenta menor assimetria: 50\% da área de pastagens da amostra é composta por pastagens plantadas e, em metade dos municípios da amostra, esse percentual é inferior a 50\% (mediana). O mesmo ocorre para o caso da área trabalhada como proporção da área aproveitável (X3), o que indica o potencial de intensificação do uso da terra.

A respeito da proporção de lavouras permanentes e temporárias sobre a área aproveitável (X4), os municípios possuem média de $26 \%$, mediana de $19 \%$ e amplitude elevada. A proporção média de estabelecimentos que obteve financiamento (X7) é de 19\%. Preocupa ainda o fato de que, em metade dos municípios da amostra, menos de $15 \%$ dos estabelecimentos obteve financiamentos, enquanto municípios como Barra Funda (RS), Novo Xingú (RS) e Xavantina (SC) tiveram mais de $75 \%$ de seus estabelecimentos financiados. ${ }^{5}$

As proporções médias de estabelecimentos que realizaram despesas com adubos (X17), corretivos do solo (X18), sementes e mudas (X19) e agrotóxicos (X20) foram de 37\%, 13\%, 17\% e 31\%, respectivamente, indicando baixa adoção desses insumos. Os percentuais médios de estabelecimentos que realizaram despesas com sal e ração para animais (X14), compra de animais (X21) e compra de medicamentos para animais (X22) foram, respectivamente, de 43\%, 25\% e 62\%.

O percentual médio de estabelecimentos que utilizaram técnicas de plantio em nível (X9), plantio direto na palha (X10) e rotação de culturas (X11) foi, respectivamente, de $32 \%, 13 \%$ e $14 \%$, valores expressivamente baixos. As medianas dessas variáveis apresentaram valores abaixo das médias, apontando para distribuições assimétricas à direita, com forte concentração de municípios nos quais o percentual de adoção dessas técnicas é muito baixo, sobretudo o plantio direto e a rotação de culturas.

O índice médio de escolaridade dos dirigentes dos estabelecimentos (X24) é de 0,41 , ilustrando a baixa qualificação encontrada no meio rural brasileiro. Ainda mais preocupante é o grau de orientação recebida (X25), com índice médio de 0,22 (em uma escala de zero a um), o que contribui para a persistência de um perfil médio de agricultor pouco qualificado. Essa é uma das características mais marcantes do perfil dos produtores, uma vez que, dentro do pacote de modernização baseado em crédito, garantia de preços e pesquisa e extensão rural, a atenção dada a essa última faceta é sempre menor e mais concentrada regionalmente.

Metade dos municípios brasileiros apresentam nível de integração de seus estabelecimentos com o mercado (X30) inferior a 0,52, o que reflete a desvinculação de boa parte dos estabelecimentos da venda de seus produtos ao mercado, devido aos maiores níveis de eficiência e produtividade exigidos e que poderiam pos-

5 Os dados não levam em consideração se houve tentativa frustrada de obtenção de financiamentos por parte dos estabelecimentos. 
sibilitar melhores oportunidades aos pequenos agricultores. Uma das estratégias de acesso a tais mercados é a formação de cooperativas ou entidades de classe (X29), que possibilitam maior poder de barganha aos pequenos produtores tanto na venda de seus produtos quanto na compra de insumos modernos e na difusão de conhecimento de técnicas de produção e comercialização. Todavia, existem ainda muitos municípios em que o cooperativismo é pouco difundido/adotado.

Devido ao (in)acesso aos mercados mais dinâmicos, muitos estabelecimentos se caracterizam pela produção diversificada e de subsistência, com baixo grau de especialização (X27 e X28). A diversificação produtiva não é em si um aspecto negativo em termos de modernização. Porém, assumindo-se que o pacote de modernização impõe escalas mínimas eficientes de produção para acessar os mercados mais dinâmicos, a diversificação em estabelecimentos de menor porte se associa à produção para subsistência e/ou à venda em mercados menos dinâmicos. Por fim, as variáveis ligadas à geração de valor econômico - PIB/AA (X15) e PIB/EHA (X16) - apresentam grandes diferenças entre os municípios e relativa concentração de municípios abaixo dos níveis médios nacionais.

As evidências de disparidade entre os municípios se mostram presentes já na análise descritiva, dada a coexistência de municípios com nenhum estabelecimento, utilizando-se de força mecânica, como os casos de Muaná (PA) e Piraí do Norte (BA), e de municípios nos quais mais de $95 \%$ dos estabelecimentos fazem o uso de força mecânica, como Sapezal (MT) e Colorado (PR). Os coeficientes de variação demonstram a desigualdade existente entre os municípios brasileiros, sobretudo no que diz respeito ao plantio direto (X10), ao valor das máquinas e veículos por trabalhador (X13) e por área de lavoura (X12), ao número de tratores por trabalhador (X5), ao PIB da agropecuária por hectare (X15) e por trabalhador (X16) e às despesas com corretivos do solo (X18) e sementes e mudas (X19). Essas variáveis apresentaram os maiores coeficientes de variação entre os 30 indicadores analisados.

A Tabela 2 ilustra os resultados do teste de adequação da amostra de Kaiser-Mayer-Olkin (KMO) parciais e total e do teste de esfericidade de Bartlett.

Tabela 2 - Medidas e testes de adequação da amostra

\begin{tabular}{llllll}
\hline Kaiser-Mayer-Olkin total & \multicolumn{7}{c}{ Kaiser-Mayer-Olkin parcial } & \multicolumn{2}{c}{0} \\
\hline Variável & Valor & Variável & Valor & Variável & Valor \\
\hline X1 & 0,97 & X11 & 0,96 & X21 & 0,98 \\
X2 & 0,94 & X12 & 0,96 & X22 & 0,95 \\
X3 & 0,94 & X13 & 0,94 & X23 & 0,98 \\
X4 & 0,94 & X14 & 0,95 & X24 & 0,97 \\
X5 & 0,93 & X15 & 0,94 & X25 & 0,97 \\
\hline
\end{tabular}

Continua... 
Conclusão.

\begin{tabular}{llllll}
\hline Kaiser-Mayer-Olkin total & \multicolumn{7}{c}{0} & 0,96 \\
\hline Variável & Valor & Variável & Valor & Variável & Valor \\
\hline X6 & 0,95 & X16 & 0,93 & X26 & 0,97 \\
X7 & 0,97 & X17 & 0,96 & X27 & 0,90 \\
X8 & 0,98 & X18 & 0,97 & X28 & 0,93 \\
X9 & 0,98 & X19 & 0,98 & X29 & 0,99 \\
X10 & 0,92 & X20 & 0,98 & X30 & 0,95 \\
\hline Teste de esfericidade de Bartlett & & & Chi-squared & & $289.981,50$ \\
Gl & & & 435,00 & & \\
$P$-valor & & & 0,00 & & \\
\hline
\end{tabular}

Fonte: Elaboração própria.

Os testes apontam, em ambos os casos, que a amostra é adequada para a realização de análise fatorial. A medida KMO apresentou o valor de 0,96 no teste conjunto da base de dados e valores superiores a 0,90 para todas as variáveis separadamente. Pelo teste de Bartllet, rejeita-se a hipótese nula de que a matriz de correlação seja uma matriz identidade ao nível de significância de $1 \%$.

Uma vez que os testes apontam para uma satisfatória adequação da amostra para a análise fatorial, foi realizada a extração de fatores. Inicialmente, foi utilizada a análise de componentes principais para extração e definição do número ótimo e, posteriormente, a extração foi realizada por máxima verossimilhança (método mais robusto), utilizando-se três critérios de definição do número de fatores a serem extraídos: o critério do autovalor > 1; o gráfico de declive; e a determinação do número ótimo de componentes principais por meio de validação cruzada, conforme a metodologia de Josse e Husson (2012). Após essa etapa, os fatores extraídos foram rotacionados pelo método promax.

\section{Resultados}

Os resultados obtidos pela aplicação do teste de Josse e Husson (2012) apontam para um número ótimo de quatro componentes principais. A Figura 1 consiste no gráfico de declive. A partir do quarto componente principal, os autovalores assumem valores inferiores a um, corroborando os resultados do teste de Josse e Husson (2012) e, portanto, são desconsiderados da análise. Seguindo-se os critérios citados, foram extraídos quatro fatores pelo método da máxima verossimilhança e rotacionados pelo método promax. 
Figura 1 - Gráfico de declive (scree plot)

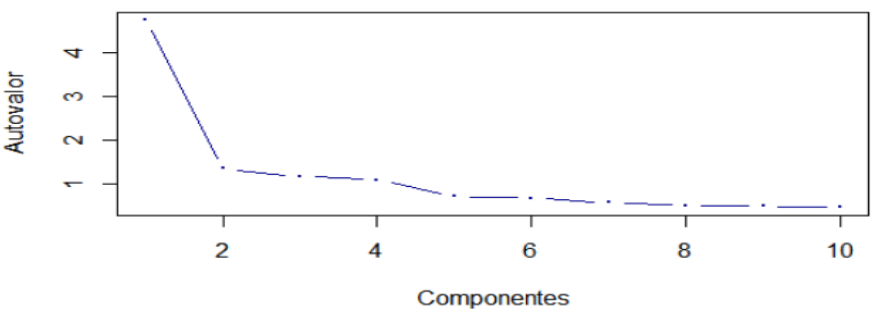

Fonte: Elaboração própria a partir dos resultados da pesquisa.

A Tabela 3 ilustra os valores da soma dos quadrados das cargas fatoriais (SS loadings), a proporção da variância explicada por cada fator e a variância acumulada, e, por sua vez, a Tabela 4 ilustra as cargas fatoriais, as comunalidades, as especificidades e indica o fator associado, tendo como critérios a carga fatorial igual ou superior a 0,5 .

Tabela 3 - Percentual de variância explicada e especificidade

\begin{tabular}{lllll}
\hline & Fator 1 & Fator 2 & Fator 3 & Fator 4 \\
\hline SS loadings & 6,797 & 4,932 & 4,677 & 2,783 \\
Proporção da variância & 0,227 & 0,164 & 0,156 & 0,093 \\
Variância cumulativa & 0,227 & 0,391 & 0,547 & 0,640 \\
\hline
\end{tabular}

Fonte: Elaboração própria a partir dos resultados da pesquisa.

Tabela 4 - Comunalidades, especificidades e cargas fatoriais

\begin{tabular}{|c|c|c|c|c|c|c|c|}
\hline \multirow[b]{2}{*}{ Variável } & \multicolumn{2}{|c|}{ Cargas fatoriais } & \multirow[b]{2}{*}{$\begin{array}{c}\text { Fator } \\
2 \\
\end{array}$} & \multirow[b]{2}{*}{ Fator 4} & \multirow[b]{2}{*}{$\begin{array}{l}\text { Comunali- } \\
\text { dade }\end{array}$} & \multirow[b]{2}{*}{$\begin{array}{l}\text { Especifi- } \\
\text { cidade }\end{array}$} & \multirow[b]{2}{*}{$\begin{array}{r}\text { Fator as } \\
\text { sociado }\end{array}$} \\
\hline & $\begin{array}{c}\text { Fator } \\
\quad 1\end{array}$ & Fator 3 & & & & & \\
\hline X03 & $\underline{0.50}$ & 0.36 & 0.02 & 0.16 & 0.89 & 0.11 & Fator 1 \\
\hline X04 & $\underline{0.53}$ & -0.12 & 0.33 & 0.27 & 0.83 & 0.17 & Fator 1 \\
\hline X09 & $\underline{0.74}$ & -0.06 & 0.22 & 0.09 & 0.85 & 0.15 & Fator 1 \\
\hline X15 & $\underline{1.01}$ & -0.11 & 0.05 & -0.29 & 0.64 & 0.36 & Fator 1 \\
\hline $\mathrm{X} 18$ & $\underline{0.85}$ & -0.13 & 0.14 & 0.10 & 0.86 & 0.14 & Fator 1 \\
\hline $\mathrm{X} 23$ & $\underline{0.54}$ & 0.44 & 0.09 & 0.00 & 0.96 & 0.04 & Fator 1 \\
\hline $\mathrm{X} 24$ & $\underline{0.50}$ & 0.39 & 0.01 & 0.21 & 0.98 & 0.02 & Fator 1 \\
\hline $\mathrm{X} 27$ & $\underline{0.93}$ & 0.20 & -0.40 & 0.14 & 0.89 & 0.11 & Fator 1 \\
\hline X30 & $\underline{0.63}$ & 0.36 & 0.06 & 0.02 & 0.98 & 0.02 & Fator 1 \\
\hline
\end{tabular}

Continua... 
Conclusão.

\begin{tabular}{llllllll}
\hline X02 & 0.43 & $\underline{\mathbf{0 . 6 2}}$ & -0.23 & 0.07 & 0.77 & 0.23 & Fator 2 \\
X08 & 0.25 & $\underline{\mathbf{0 . 5 1}}$ & 0.20 & 0.11 & 0.90 & 0.10 & Fator 2 \\
X14 & -0.17 & $\underline{\mathbf{1 . 0 5}}$ & 0.03 & 0.02 & 0.94 & 0.06 & Fator 2 \\
X21 & -0.16 & $\underline{\mathbf{0 . 7 5}}$ & 0.49 & -0.10 & 0.90 & 0.10 & Fator 2 \\
X22 & 0.00 & $\underline{\mathbf{0 . 9 3}}$ & 0.04 & 0.04 & 0.97 & 0.03 & Fator 2 \\
X28 & 0.30 & $\underline{\mathbf{0 . 6 4}}$ & 0.14 & -0.04 & 0.92 & 0.08 & Fator 2 \\
X07 & 0.10 & 0.18 & $\underline{\mathbf{0 . 7 3}}$ & 0.03 & 0.90 & 0.10 & Fator 3 \\
X10 & -0.25 & -0.11 & $\underline{\mathbf{0 . 8 6}}$ & 0.26 & 0.67 & 0.33 & Fator 3 \\
X11 & 0.06 & -0.04 & $\underline{\mathbf{0 . 8 4}}$ & 0.00 & 0.73 & 0.27 & Fator 3 \\
X19 & -0.02 & 0.28 & $\underline{\mathbf{0 . 7 8}}$ & -0.09 & 0.83 & 0.17 & Fator 3 \\
X05 & 0.05 & -0.03 & 0.15 & $\underline{\mathbf{0 . 8 7}}$ & 0.99 & 0.01 & Fator 4 \\
X06 & -0.03 & 0.05 & 0.44 & $\underline{\mathbf{0 . 6 0}}$ & 0.93 & 0.07 & Fator 4 \\
X13 & -0.19 & 0.18 & 0.02 & $\underline{\mathbf{0 . 8 3}}$ & 0.71 & 0.29 & Fator 4 \\
X16 & 0.36 & -0.11 & -0.02 & $\underline{\mathbf{0 . 6 5}}$ & 0.71 & 0.29 & Fator 4 \\
X17 & $\underline{\mathbf{0 . 6 9}}$ & -0.10 & $\underline{\mathbf{0 . 5 1}}$ & -0.08 & 0.95 & 0.05 & Cross- \\
& & & & & & & loading \\
X20 & $\mathbf{0 . 5 8}$ & -0.11 & $\underline{\mathbf{0 . 6 0}}$ & -0.04 & 0.93 & 0.07 & Cross- \\
& & & & & 0.09 ling \\
X26 & $\underline{\mathbf{0 . 5 0}}$ & $\underline{\mathbf{0 . 5 2}}$ & 0.06 & 0.01 & 0.97 & 0.03 & Cross- \\
X01 & 0.37 & 0.10 & 0.35 & 0.29 & 0.93 & 0.07 & loading \\
X12 & 0.31 & 0.18 & 0.43 & -0.05 & 0.61 & 0.39 & - \\
X25 & 0.39 & 0.06 & 0.34 & 0.29 & 0.91 & 0.09 & - \\
X29 & 0.35 & 0.36 & 0.35 & -0.02 & 0.87 & 0.13 & - \\
\hline & & & & & & &
\end{tabular}

Fonte: Elaboração própria.

O conjunto dos quatro fatores extraídos explica 64\% da variância total dos dados. O primeiro fator rotacionado explica $22,7 \%$ da variância total, o segundo explica $16,4 \%$, o terceiro responde por $15,6 \%$ da variância e o quarto, por 9,3\%. Lembrando que, ao partir de variáveis originais padronizadas (média zero e variância um), os escores fatoriais também possuem média zero. Logo, todos os municípios que apresentam escores positivos em algum dos quatro fatores estão à frente ou acima da média nacional nesse aspecto do processo de modernização agropecuária.

As variáveis X3 (área trabalhada/AA), X4 (área com lavouras permanentes e temporárias/AA), X9 (estabelecimentos que utilizaram técnicas de plantio em nível/TE), X15 (PIB da agricultura/AA), X18 (estabelecimentos que realizaram despesas com corretivos do solo/TE) e X23 (estabelecimentos que utilizam energia elétrica/TE) estão positiva e fortemente correlacionadas ao fator um. Além delas, as variáveis X17 (despesas com adubos), X20 (despesas com agrotóxicos) e X26 
(índice de suplementação animal) também apresentaram carga fatorial superior a 0,5 para esse fator, ainda que em situação de cross-loading. Como essas variáveis estão associadas à lucratividade e ao uso intensivo do solo, sustentado pelo uso de adubos e defensivos, esse fator será denominado de "uso intensivo da terra".

As variáveis X2 (área de pastagem plantada/AP), X8 (estabelecimentos que realizaram despesas com combustíveis/TE), X14 (estabelecimentos que realizaram despesas com sal e ração para animais/TE), X21 (estabelecimentos que realizaram despesas com compra de animais/TE), X22 (estabelecimentos que realizaram despesas com medicamentos para animais/TE) e X28 (estabelecimentos especializados/TE) estão positiva e fortemente correlacionadas ao fator dois. Além delas, a variável X26 (índice de suplementação animal) também apresentou carga fatorial superior a 0,5 para esse fator, embora em situação de cross-loading. Como essas variáveis refletem características da criação animal tecnificada (bovinos, suínos, aves e outros animais) e de sua capitalização via compra de animais, esse fator será denominado de "capitalização e tecnificação da criação animal".

As variáveis X7 (estabelecimentos que tiveram financiamentos no ano de referência/TE), X10 (estabelecimentos que utilizaram técnicas de plantio direto na palha/TE), X11 (estabelecimentos que utilizaram técnicas de rotação de cultura/TE) e X19 (estabelecimentos que realizaram despesas com sementes e mudas/TE) estão positiva e mais fortemente correlacionadas com o fator três. Além delas, as variáveis X17 (despesas com adubos), X20 (despesas com agrotóxicos) e X26 (índice de suplementação animal) também apresentaram carga fatorial superior a 0,5 para esse fator, ainda que em situação de cross-loading. Essas variáveis representam o conhecimento e a adoção de técnicas produtivas adequadas à produção em larga escala na agricultura. Portanto, esse fator será denominado de "tecnificação agrícola".

As variáveis X5 (número de tratores/EHA), X6 (número de máquinas e implementos agrícolas/EHA), X13 (valor dos veículos, tratores, máquinas e implementos/EHA) e X16 (PIB da agricultura/EHA) estão positiva e mais fortemente correlacionadas com o fator quatro. Por refletirem as relações entre o emprego de mão de obra e de capital na agropecuária, esse fator será denominado de "relação capital-trabalho".

A Tabela 5 ilustra o escore médio de cada região político-administrativa do Brasil, porém enfatiza o percentual de municípios que possuem escores positivos (estão acima da média nacional) em cada região.

Tabela 5 - Percentual de municípios com escore fatorial positivo e escore médio por região

\begin{tabular}{lccccc}
\hline Escore médio regional & $\mathbf{N}$ & $\mathbf{N E}$ & $\mathbf{S E}$ & $\mathbf{S}$ & $\mathbf{C O}$ \\
$\mathrm{F}_{1}$ : uso intensivo da terra & -0.09 & 0.13 & 0.58 & -0.58 & -0.76 \\
$\mathrm{~F}_{2}$ : capitalização e tecnificação da criação animal & 0.92 & -0.22 & -0.29 & -0.08 & 1.16 \\
\hline
\end{tabular}

Continua... 


\begin{tabular}{lccccc}
\hline $\mathrm{F}_{3}$ : tecnificação agrícola & -0.76 & -0.26 & -0.35 & 1.31 & -0.84 \\
$\mathrm{~F}_{4}$ : relação capital-trabalho & -0.27 & -0.09 & 0.11 & -0.33 & 1.01 \\
Percentual de municípios com escore positivo & & & & & \\
$\mathrm{F}_{1}$ : uso intensivo da terra & $20 \%$ & $26 \%$ & $35 \%$ & $20 \%$ & $8 \%$ \\
$\mathrm{~F}_{2}$ : capitalização e tecnificação da criação animal & $46 \%$ & $12 \%$ & $20 \%$ & $31 \%$ & $66 \%$ \\
$\mathrm{~F}_{3}$ : tecnificação agrícola & $1 \%$ & $6 \%$ & $12 \%$ & $74 \%$ & $6 \%$ \\
$\mathrm{~F}_{4}$ : relação capital-trabalho & $36 \%$ & $44 \%$ & $55 \%$ & $32 \%$ & $69 \%$ \\
\hline
\end{tabular}

Fonte: Elaboração própria a partir dos resultados da pesquisa.

Mesmo as regiões tradicionalmente apontadas como modernas na literatura (Sul, Sudeste e Centro-Oeste) apresentaram escore médio negativo em alguns casos, ou mesmo inferiores aos de regiões como o Norte e Nordeste. Isso revela a coexistência de diversos graus de modernização em uma mesma região, evidenciando a heterogeneidade intrarregional.

A região Norte representou cerca de $18 \%$ do rebanho bovino brasileiro em 2006 (IBGE, 2009) e nela destaca-se o percentual de municípios com escore positivo no caso da capitalização e tecnificação da criação animal (46\%). Na região Nordeste, o maior percentual de municípios com escore positivo ocorreu no caso da relação capital-trabalho (44\%), porém o escore médio se mantém negativo (-0,09). Na região Sudeste, os destaques são a relação capital-trabalho e o uso intensivo da terra, que apresentaram escore médio positivo e os maiores percentuais de municípios com escore positivo. A região Sul, por sua vez, é responsável pelo maior escore médio no aspecto tecnificação agrícola e possui 74\% de seus municípios com escore acima da média nacional nesse quesito. Por fim, na região Centro-Oeste, o destaque se dá na relação capital-trabalho e na capitalização e tecnificação da criação animal. Essa região representou cerca de 34\% do rebanho bovino brasileiro em 2006 (IBGE, 2009) e é conhecida pelo uso intensivo de capital na produção agrícola.

A Figura 2 ilustra a divisão dos escores fatoriais em dez classes (nove decis) e a classificação dos municípios com relação ao fator um (uso intensivo da terra). As demais figuras, que ilustram o panorama regional dos outros aspectos da modernização, foram classificadas da mesma forma: dez classes tendo como separatrizes os nove decis de cada fator. 
Figura 2 - Classificação dos municípios "modernos" sob o aspecto uso intensivo da terra

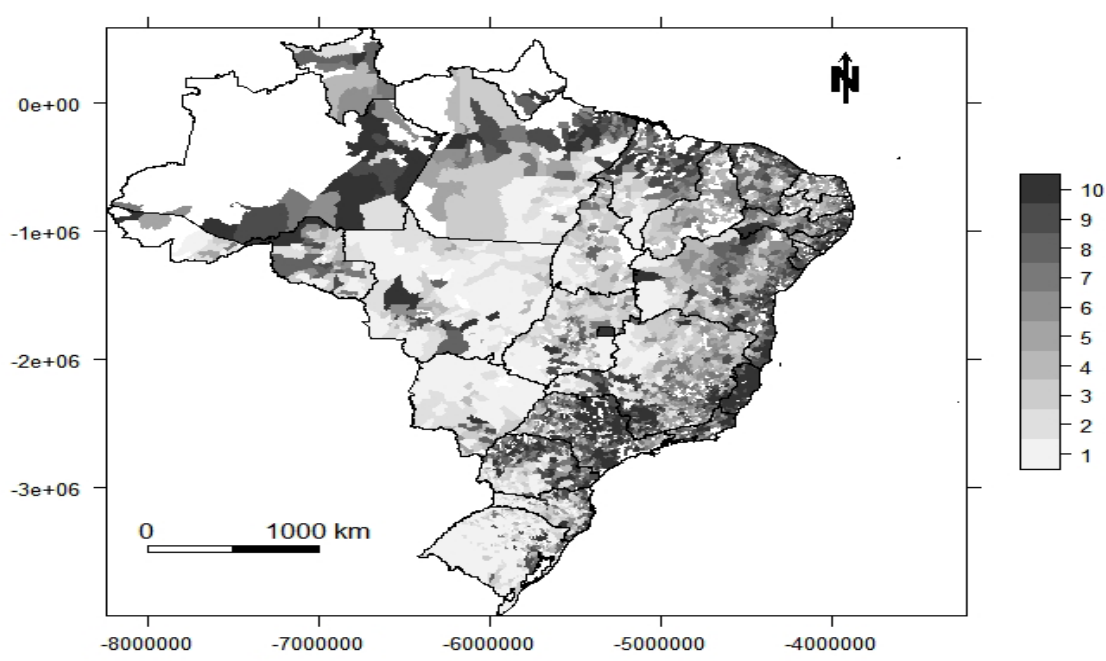

Fonte: Elaboração própria.

A região de maior destaque nesse caso é o Sudeste, que possui um escore médio de 0,58 e $35 \%$ de seus municípios com escores positivos nesse fator, que caracteriza os estabelecimentos integrados aos mercados mais dinâmicos e, sobretudo, que adotam tecnologias e técnicas poupadoras de terra, como adubos, corretivos do solo, sistemas de plantio em nível e maior aproveitamento das áreas agricultáveis. Isso permite atingir maiores níveis de lucratividade. Esses municípios se concentram nos estados de São Paulo e Espírito Santo e na região sul de Minas Gerais. Esse fator se assemelha aos fatores denominados intensidade de exploração da terra por Hoffmann e Kageyama (1985) e Hoffmann e Kassouf (1989a; 1989b) e corrobora os resultados desses trabalhos nesse aspecto, demonstrando que estados como São Paulo, Paraná, Santa Catarina, Alagoas, Rio de Janeiro e Espírito Santo apresentam elevado grau de modernização nesse aspecto. A exceção se dá no caso do Rio Grande do Sul, que apresenta alto grau de modernização na análise de Hoffmann e Kageyama (1985), ao contrário do ilustrado na Figura 2.

As regiões Norte e Nordeste estão muito próximas à média nacional nesse aspecto com escores médios de $-0,09$ e 0,13, respectivamente. Porém, possuem uma parcela pequena de municípios que apresentam escores positivos ( $20 \% \mathrm{e}$ $26 \%$, respectivamente). Os estabelecimentos mais lucrativos e integrados aos mercados mais dinâmicos da região Nordeste estão concentrados na faixa litorânea, 
englobando diversos estados na região da Zona da Mata e Vale do São Francisco. A região do agreste e do sertão nordestino é caracterizada por poucos municípios com escore positivo nesse fator, sobretudo no estado do Piauí, conhecido pelo clima extremo e pela pobreza no campo. As adversidades climáticas da região e a falta de infraestrutura (como a irrigação) para superar tais problemas representam um grande entrave para o desenvolvimento da agropecuária. Ainda que haja terra disponível e aproveitável para as atividades agropecuárias, as condições estruturais e a falta de estratégias para superar as adversidades climáticas limitam o aproveitamento dos recursos naturais.

O Sul e o Centro-Oeste apresentaram escores médios de -0,58 e -0,76, respectivamente, e baixa concentração de municípios modernos sob esse aspecto (20\% e 8\%, respectivamente). Essas regiões são frequentemente associadas à agricultura moderna na literatura relacionada, porém apresentaram um pequeno percentual de municípios com escores acima da média nacional nesse fator. $\mathrm{O}$ desempenho negativo dessas regiões nesse aspecto está relacionado às atividades produtivas que requerem grandes extensões de terra para sua realização. Todavia, em outros aspectos da modernização, essas regiões se destacam positivamente.

A parcela de municípios com escores positivos nesses aspectos está situada na região noroeste do estado do Paraná, na divisa litorânea do Paraná com Santa Catarina e nas mesorregiões noroeste riograndense e metropolitana de Porto Alegre, regiões que possivelmente têm um consumo reduzido de adubos e corretivos do solo devido a sua fertilidade natural. O mesmo ocorre na região Centro-Oeste, que possui agrupamentos de municípios modernos sob esse aspecto em regiões específicas dos estados de Mato Grosso (meridional), Mato Grosso do Sul (mesorregião sudoeste) e Goiás (mesorregião centro de Goiás).

A Figura 3 ilustra a classificação dos municípios com relação ao fator dois (capitalização e tecnificação da criação animal). 
Figura 3 - Classificação dos municípios "modernos" sob o aspecto capitalização e tecnificação da criação animal

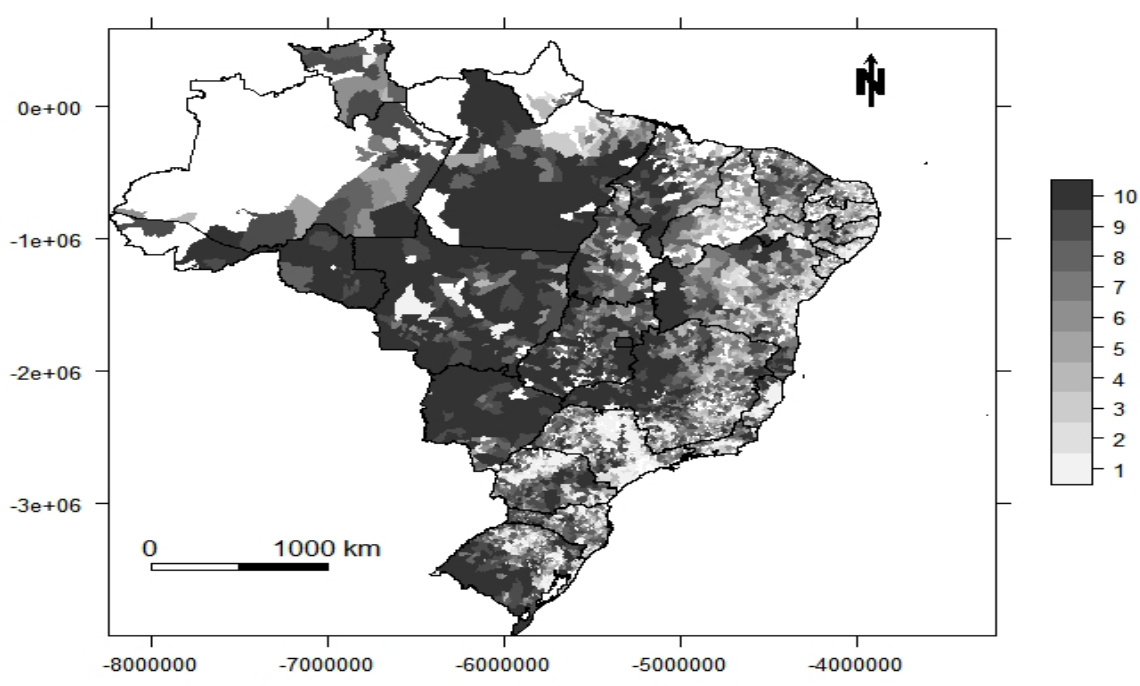

Fonte: Elaboração própria.

Com relação ao fator dois, nota-se uma distribuição menos concentrada de municípios modernos. O Centro-Oeste e o Norte apresentaram os maiores escores médios (1,16 e 0,92 , respectivamente), bem como as maiores parcelas de municípios acima da média nacional ( $66 \%$ e $46 \%$, respectivamente). Além de serem responsáveis por grande parte do rebanho brasileiro de bovinos e bubalinos, essas regiões se caracterizam pela adoção de práticas adequadas e modernas em grande parte de seus municípios. A maior concentração se dá nos estados de Goiás, Mato Grosso, Mato Grosso do Sul, Tocantins, Pará e Rondônia.

As regiões Sul e Sudeste, embora com escores médios negativos, se encontram próximas à média nacional e com um percentual expressivo de municípios com escores positivos ( $31 \%$ e $20 \%$, respectivamente). Destacam-se o oeste paulista, o sul de Minas Gerais, o sul do Rio Grande do Sul e a faixa oeste que liga os estados do Paraná, Santa Catarina e Rio Grande do Sul. O Nordeste, por sua vez, apresentou escore médio negativo $(-0,22)$ e pequeno percentual de municípios modernos nesse aspecto (12\%), que se dispersam, principalmente, pelos estados do Maranhão, Ceará e Bahia, demonstrando o baixo grau de modernização da região também nesse aspecto. A Figura 4 ilustra a classificação dos municípios com relação ao fator três (tecnificação agrícola). 
Figura 4 - Classificação dos municípios "modernos" sob o aspecto tecnificação agrícola

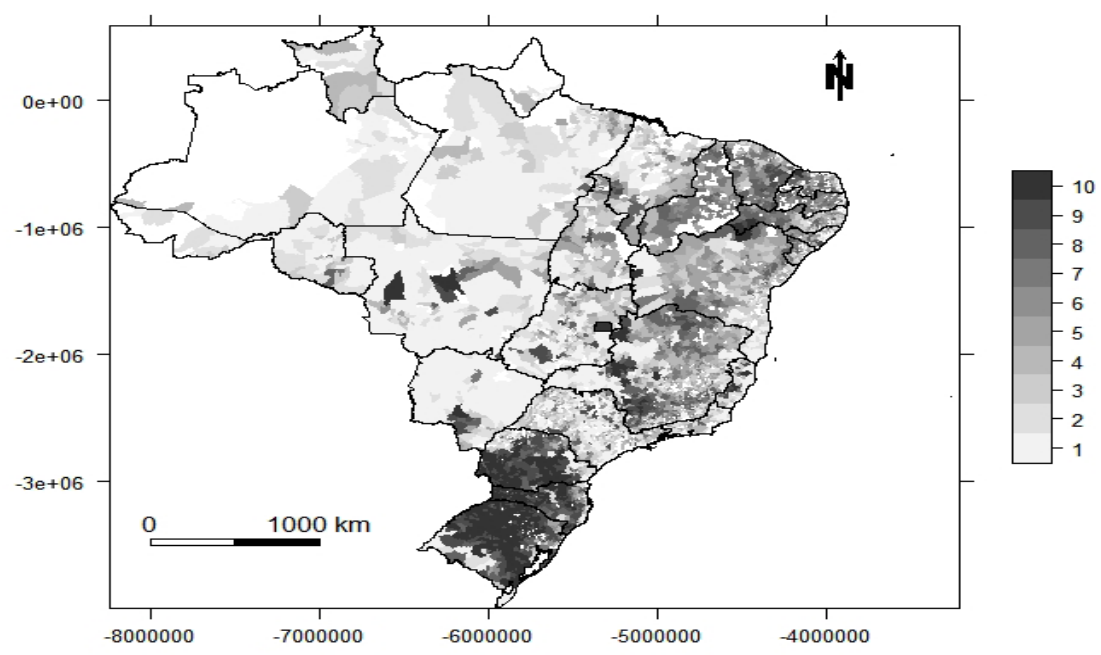

Fonte: Elaboração própria.

Com relação ao fator três, a região Sul se destaca com um escore médio bastante superior $(1,31)$ ao das demais regiões e com um grande percentual de municípios com escores positivos (74\%), que se distribuem por praticamente todo o estado do Paraná e de Santa Catarina e pela parte setentrional do estado do Rio Grande do Sul, que tem como principais atividades agropecuárias a produção de soja, uva, fumo e horticultura (FUNDAÇÃO DE ECOMONIA E ESTATÍSTICA, 2015). Esses municípios são caracterizados pela adoção de práticas agrícolas voltadas para a eficiência (como a compra de sementes e mudas selecionadas e uso de defensivos), elevado grau de mecanização, capitalização e acesso ao crédito.

A região Sudeste apresentou escore médio negativo $(-0,35)$ nesse fator, e seus municípios com escore positivo se concentram na região setentrional do estado de São Paulo, no sul de Minas Gerais e no Espírito Santo. O Centro-Oeste, por sua vez, possui apenas $6 \%$ de seus municípios com escores positivos, o que novamente destaca a heterogeneidade existente em uma região considerada símbolo da agricultura moderna. Norte e Nordeste apresentam baixos escores médios neste fator (- 0,76 e $-0,26$, respectivamente) e poucos municípios com escores positivos, concentrados no estado do Ceará e na parcela da Bacia do Rio São Francisco, que compõe as divisas dos estados da Bahia com Pernambuco e Sergipe com Alagoas.

O fator dois (capitalização e tecnificação da criação animal) e o fator três (tecnificação agrícola) se assemelham aos fatores grau de mecanização, nível de 
financiamento e investimento na agricultura e intensidade do uso de capital encontrados em trabalhos como os de Hoffmann e Kageyama (1985), Souza e Lima (2003) e Corrêa e Figueiredo (2006), com a vantagem de diferenciar entre o grau de capitalização na agricultura e na criação animal. Embora os resultados não sejam diretamente comparáveis, esses trabalhos apontam para estados como São Paulo, Santa Catarina, Rio Grande do Sul, Distrito Federal, Goiás, Paraná e Mato Grosso do Sul como destaques, sobretudo com relação à tecnificação agrícola. Foi possível demonstrar que, embora a modernização da criação animal esteja mais difundida entre os municípios, no caso da agricultura é regionalmente mais concentrada, sobretudo em regiões de proeminência na produção agrícola. A Figura 5 ilustra a classificação dos municípios com relação ao fator quatro (relação capital-trabalho).

Figura 5 - Classificação dos municípios "modernos" sob o aspecto relação capitaltrabalho

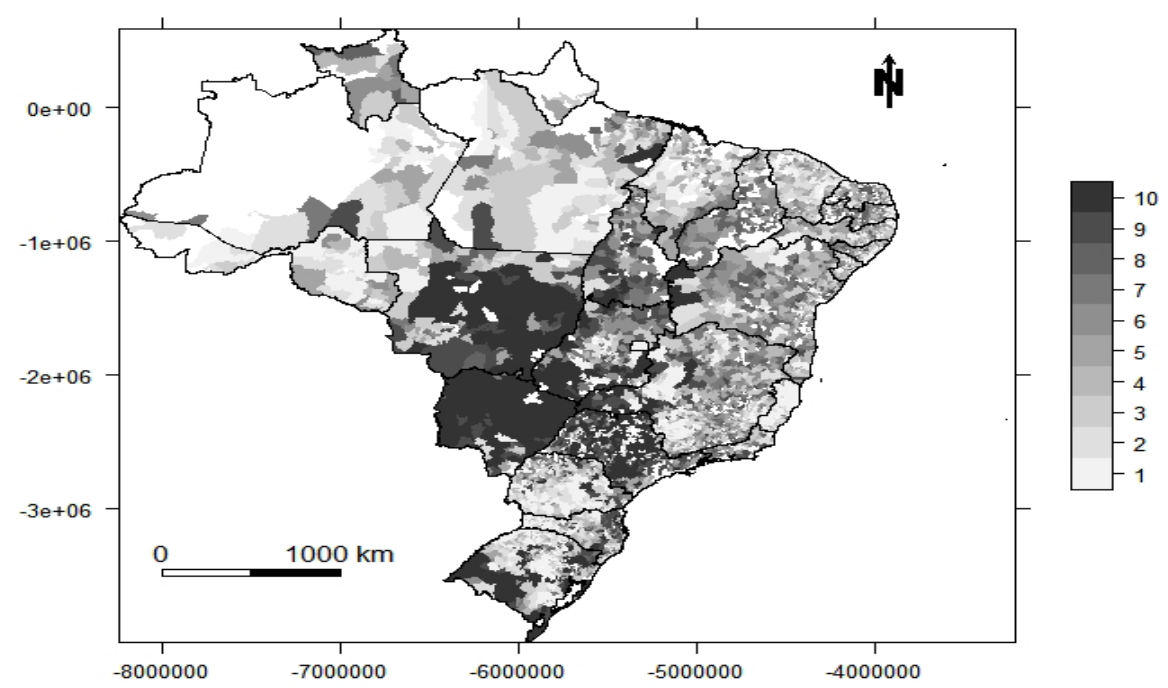

Fonte: Elaboração própria.

Por fim, com relação ao fator quatro, nota-se que os maiores escores médios são apresentados pelas regiões Sudeste e Centro-Oeste, bem como os maiores percentuais de municípios com escores acima da média nacional. Destaca-se a região Centro-Oeste, associada ao uso intensivo de maquinários de grande porte para a agricultura, como tratores e colheitadeiras e pelo nível relativamente baixo de mão de obra empregada. A região possui $69 \%$ de seus municípios com escores positivos e bem distribuídos entre Mato Grosso, Mato Grosso do Sul, Goiás, Tocantins e Distrito Federal e um escore médio de 1,01. 
A região Sudeste possui 55\% de municípios com escores positivos nesse fator, concentrados fortemente no estado de São Paulo e no Triângulo Mineiro. Nos demais estados da região, a frequência de municípios modernos é expressivamente menor. Destaca-se o Espírito Santo, que, embora tenha apresentado altos percentuais de municípios com escores positivos sob os outros fatores, nesse caso apresentou o contrário, o que provavelmente se dá devido ao relevo montanhoso do estado, que inviabiliza a mecanização e aumenta a quantidade de mão de obra empregada na lavoura. Na região Sul, os municípios com escore positivo para este fator estão concentrados no Rio Grande do Sul, faixa leste de Santa Catarina e Noroeste do Paraná, na divisa com o estado de São Paulo.

O fator quatro é similar ao fator "grau de mecanização e modernização das relações de trabalho", estabelecido por Hoffmann e Kageyama (1985), que também apontam para estados das regiões Sul e Sudeste como os mais modernizados nesse aspecto.

Hoffmann e Kageyama (1985) e Hoffmann e Kassouf (1989a; 1989b) apontam que, nas décadas de 1970 e 1980, havia forte diferença em termos de modernização entre as regiões Centro-Sul e as demais. O que parece ter se modificado, desde então, é que algumas partes das regiões Norte e Nordeste evoluíram em termos de modernização, ainda que de forma desigual e em aspectos específicos do processo. A região Norte, por exemplo, se destaca no caso da pecuária, enquanto a faixa litorânea da região Nordeste, o Vale do São Francisco e a região do Matopiba apresentam destaques em termos de modernização agrícola na região Nordeste.

Ainda que a modernização da agropecuária seja um fenômeno multifacetado e dinâmico, o que permite retratar os diferentes graus de modernização sob diferentes pontos de vista, destaca-se o caso da região Nordeste, que, embora tenha evoluído no processo de modernização, apresentou escores médios relativamente baixos em quase todos os aspectos analisados. Isso demonstra a precariedade estrutural, as adversidades edafoclimáticas enfrentadas e a vulnerabilidade produtiva no que diz respeito às condições de competição com as demais regiões produtoras e à integração ao mercado.

Os percentuais de municípios modernos do Nordeste conformam alguns polos e demonstram que, ainda que seja um grande desafio elevar ao mais alto nível as condições produtivas e o desempenho dessa região, é possível melhorá-los com a difusão de políticas de pesquisa e extensão rural, capacitação e escolarização da mão de obra, infraestrutura produtiva e logística e minimização dos efeitos adversos do clima.

Chama a atenção o fato desse conjunto de políticas estar diretamente relacionado aos "serviços gerais para a agricultura", que Tangermann (2005) demonstra ser o aspecto que menos recebe recursos governamentais. É claro que as políticas de destinação de recursos ao produtor, como o crédito subsidiado, a garantia de preços mínimos e a distribuição de terras, possuem papel relevante, mas têm seus 
efeitos parcial ou totalmente neutralizados quando inexistem condições estruturais adequadas para o bom uso desses recursos públicos investidos.

\section{Considerações Finais}

A evolução da agropecuária brasileira dos anos 1950 a meados dos anos 2000 é inegável, bem como a contribuição que o processo de modernização teve para tal. Todavia, persiste ainda grande heterogeneidade produtiva e econômica em nível regional, o que possibilita a coexistência de produtores modernos, intermediários e de milhares de agricultores que adotam técnicas "arcaicas" e são incapazes de seguir o modelo de produção atual. Parte deles acaba marginalizada, convertendo-se à produção para a subsistência ou migrando para as cidades em busca de melhores condições de vida, mantendo o abismo existente entre o "arcaico" e o "moderno", ainda que as faixas intermediárias sejam representativas.

Foram identificados como aspectos da modernização agropecuária brasileira presentes no ano de 2006 o uso intensivo da terra, a capitalização e tecnificação na criação animal, a tecnificação agrícola e a relação capital-trabalho, por meio dos quais constatou-se que as "boas práticas" da criação animal estão mais difundidas entre os municípios brasileiros quando comparadas com as "boas práticas" e o uso de insumos modernos na produção agrícola. Esta última possui um padrão de concentração regional sob tais aspectos (fatores um, três e quatro) e com forte heterogeneidade intrarregional. Dessa forma, a região Centro-Sul não pode ser vista como uma região homogênea em termos de modernização em nenhum de seus aspectos.

A revisão de literatura realizada fornece diversos indícios de um processo de modernização caracterizado pelo aumento da heterogeneidade produtiva. Todavia, aponta também para uma mudança no rumo da política agrícola a partir de meados da década de 1990, com a intensificação da reforma agrária e a criação do Pronaf e a retomada de políticas de crédito rural. Ainda assim, passados 10 anos, permanece um cenário de heterogeneidade produtiva e econômica entre os produtores brasileiros, no qual um contingente expressivo de municípios e produtores permanece à margem da agropecuária moderna, indicando que o pacote de políticas adotadas foi, senão inadequado, ao menos insuficiente para reduzir a heterogeneidade no meio rural brasileiro. O pacote formado pelo crédito subsidiado e a distribuição de terras deixou em segundo plano os serviços gerais à agropecuária, sobretudo no sentido de difundir a pesquisa e extensão e capacitar os produtores em situação mais vulnerável a gerar a infraestrutura necessária à produção. 


\section{Referências}

ALMEIDA, J. Da ideologia do progresso à ideia de desenvolvimento rural sustentável. In: ALMEIDA, J.; NAVARRO, Z. (org.). Reconstruindo a agricultura: ideias e ideais na perspectiva do desenvolvimento rural sustentável. Porto Alegre: Editora da UFRGS, 1997. p. 33-55.

BACHA, C. J. C. Economia e política agrícola no Brasil. São Paulo: Atlas, 2004.

BALSAN, R. Impactos decorrentes da modernização da agricultura brasileira. Revista Campo-Território, v. 1, n. 2, p. 123-151, 2006.

BUAINAIN, A. M. Trajetória recente da política agrícola brasileira. 1999. Tese (Doutorado) Instituto de Economia, Universidade Estadual de Campinas, Campinas, 1999.

CAMPOS, S. A. C.; PEREIRA, M. W. G.; TEIXEIRA, E. C. Trajetória de modernização da agropecuária mineira no período de 1996 a 2006. Economia Aplicada, v. 18, n. 4, p. 717-739, 2014

CORRAR, L. J.; PAULO, E.; DIAS FILHO, J. M. Análise multivariada para os cursos de Administração, Ciências Contábeis e Economia. São Paulo: Atlas, 2012.

CORREAA, A.M. C. J.; FIGUEIREDO, N. M. S. Modernização da agricultura brasileira no início dos anos 2000: uma aplicação de análise fatorial. Revista GEPEC, v. 10, n. 2, p. 82-99, 2006.

CRUZ, F. O.; RIBEIRO, C. G.; LIMA, I. B. A modernização agrícola nos municípios da mesorregião Campo das Vertentes: uma aplicação de métodos de análise multivariada. In: CONGRESSO DA SOCIEDADE BRASILEIRA DE ECONOMIA, ADMINISTRAÇÃO E SOCIOLOGIA RURAL, 44., Fortaleza, 2006. Anais [...]. Fortaleza: SOBER/BNB, 2006.

FAJARDO, S. Complexo agroindustrial, modernização da agricultura e participação das cooperativas agropecuárias no estado do Paraná. Caminhos de Geografia, v. 9, n. 27, p. 31-44, 2008.

FRANCO, J.; PEREIRA, M. F. Crescimento e modernização do setor agropecuário paranaense: no período de 1970 a 2004. Revista em Agronegócio e Meio Ambiente, v. 1, n. 2, p. 187-210, 2008.

FREITAS, C. A.; PAZ, M. V.; NICOLA, D. S. Analisando a modernização da agropecuária gaúcha: uma aplicação de análise fatorial e cluster. Análise Econômica, v. 25, n. 47, p. 121 149, 2007.

FUNDAÇÃO DE ECONOMIA E ESTATÍSTICA. Características da agropecuária do Rio Grande do Sul. Porto Alegre: Fundação de Economia e Estatística, 2015. Disponível em: https://www. fee.rs.gov.br/sinteseilustrada/caracteristicas-da-agropecuaria-do-rs/. Acesso em: 02 jan. de 2019.

GONZALEZ, B. C. R.; COSTA, S. M. A. L. Agricultura brasileira: modernização e desempenho. Teoria e Evidência Econômica, v. 5, n. 10 p. 7-35, maio 1998. 
HELFAND, S.M.; REZENDE, G.C. Brazilian agriculture in the 1990s: Impact of the policy reforms. Brasília, DF: IPEA, 2001.

HOFFMANN, R. A dinâmica da modernização da agricultura e distribuição da renda em 157 microrregiões homogêneas do Brasil. Piracicaba: Escola Superior de Agricultura Luiz de Queiroz, 1992.

HOFFMANN, R. Componentes principais e análise fatorial. Piracicaba: ESALQ, 2002.

HOFFMANN, R.; KAGEYAMA, A. Modernização da agricultura e distribuição de renda no Brasil. Pesquisa e Planejamento Econômico, v. 15, n. 1, p. 171-208, 1985.

HOFFMANN, R.; KASSOUF, A. L. Produção e modernização da agropecuária em 332 microrregiões homogêneas do Brasil - 1980. Piracicaba: ESALQ, 1989a.

HOFFMANN, R.; KASSOUF, A. L. Modernização e desigualdade na agricultura brasileira. Revista Brasileira de Economia, v. 43 n. 2, p. 273-303, 1989 b.

INSTITUTO BRASILEIRO DE GEOGRAFIA E ESTATÍSTICA. Censo Agropecuário 2006. Rio de Janeiro: Instituto Brasileiro de Geografia e Estatística, 2009. Disponível em: https://sidra. ibge.gov.br/home/pimpfbr/brasil. Acesso em: 10 jan. 2017.

JACKSON, J. E. Promax Rotation. In: ARMITAGE, P.; COLTON, T. (org.). Encyclopedia of Biostatistics. Hoboken, New Jersey: John Wiley E Sons, 2005.

JOSSE, J.; HUSSON, F. Selecting the number of components in PCA using cross-validation approximations. Computational Statistics and Data Analysis, v. 56, n. 6, p. 1869-1879, 2012.

KAGEYAMA, A. Problemas metodológicos na mensuração do emprego agrícola. 1986. Tese (Doutorado) - Instituto de Economia da Universidade Estadual de Campinas, Universidade Estadual de Campinas, Campinas, 1986.

KAGEYAMA, A. O novo padrão agrícola brasileiro: do complexo rural aos complexos agroindustriais. In: DELGADO, G. C.; GASQUES, J. G.; VILA VERDE, C. M. (org.). Agricultura e Políticas Públicas. Brasília, DF: IPEA, 1990. p. 113-223.

KAGEYAMA, A.; BERGAMASCO, S. M. P. P.; OLIVEIRA, J. A. Uma classificação dos estabelecimentos agropecuários do Brasil a partir do Censo de 2006. In: SCHNEIDER, S.; FERREIRA, B.; ALVES, F. Aspectos multidimensionais da agricultura brasileira: diferentes visões do Censo Agropecuário 2006. Brasília, DF: IPEA, 2014. p. 21-39.

LLANILO, R. F. et al. Regionalização da agricultura do estado do Paraná, Brasil. Ciência Rural, v. 36, n. 1, p. 120-127, 2006.

MARTINE, G. A trajetória da modernização agrícola: a quem beneficia?. Lua Nova, v. 1, n. 23, p. 7-37, 1991.

REZENDE, G. C.; Políticas trabalhista, fundiária e de crédito agrícola no Brasil: uma avaliação crítica. Revista de Economia e Sociologia Rural, v. 44, n. 1, p. 47-78, 2006. 
SILVA, J. G. A nova dinâmica da agricultura brasileira. Campinas: Editora da Unicamp, 1996.

SILVA, G. B.; BOTELHO, M. I. V. O processo histórico da modernização da agricultura no Brasil (1960-1979). Revista Campo-Território, v. 9, n. 17, p. 362-387, 2014.

SILVA, J. G.; KAGEYAMA, A. Emprego e relações de trabalho na agricultura brasileira: uma análise dos dados censitários de 1960, 1970, e 1975. Pesquisa e Planejamento Econômico, v. 13, n. 1, p. 235-266, 1983.

SILVA, J. G. et al. Tecnologia e campesinato: o caso brasileiro. Revista de Economia Política, v. 3, n. 4, p. 21-56, 1983.

SOUZA, P. M.; LIMA, J. E. Intensidade e dinâmica da modernização agrícola no Brasil e nas Unidades da Federação. Revista Brasileira de Economia, v. 57, n. 4, p. 795-824, 2003.

SOUZA, R. F.; KHAN, A. S. A modernização da agricultura, classificação dos municípios e concentração da terra no estado do Maranhão. Revista Econômica do Nordeste, v. 32, n. 1, p. 96-111, 2001.

TANGERMANN, S. Análise das políticas agrícolas do Brasil. Paris: OCDE, 2005.

WEDEKIN, I. A política agrícola brasileira em perspectiva. Revista de Política Agrícola, v. 14, p. 4-16, 2005.

\section{Autor correspondente:}

Rodrigo Peixoto da Silva

E-mail: rodrigo.peixoto@hotmail.com
Recebido em: 19/06/2019.

Aceito em: 24/01/2020.

\section{(cc) BY}

Este é um artigo de acesso aberto distribuído sob os termos da Creative Commons Attribution CC-BY 4.0, que permite uso irrestrito, distribuição e reprodução em qualquer meio, desde que o trabalho original seja devidamente citado. 